\title{
Unmet needs and related factors of Korean breast cancer survivors: a multicenter, cross-sectional study
}

Byung Joo Chae ${ }^{1 \dagger}$, Jihyoun Lee ${ }^{2 \dagger}$, Se Kyung Lee ${ }^{1}$, Hyuk-Jae Shin ${ }^{3}$, So-Youn Jung ${ }^{4}$, Jong Won Lee ${ }^{5}$, Zisun Kim ${ }^{6}$ Min Hyuk Lee ${ }^{2}$, Juhyung Lee ${ }^{7}$ and Hyun Jo Youn ${ }^{8^{*}}$ (D)

\begin{abstract}
Background: Identification of specific needs in patients with cancer is very important for the provision of patientcentered medical service. The aim of this study was to investigate the unmet needs and related factors of Korean breast cancer survivors.

Methods: A multicenter, cross-sectional, interview survey was performed among 332 Korean breast cancer survivors. The Comprehensive Needs Assessment Tool for cancer patients was administered to survivors who gave written informed consent to participate. Data were analyzed using t-test, ANOVA and multiple regression analysis.

Results: The level of unmet needs was highest in the domain 'Information and education' (mean \pm SD; $1.70 \pm 1.14$ ) and the item with the highest level of unmet needs was 'Needed help in coping with fear of recurrence' (2.04 \pm 1.09$)$. Unmet needs were correlated with age, stage, multiplicity, HER2, treatment state, marital status, employment, psychosocial status, and problems in EQ-5D dimensions. In multiple regression analysis, the 50-59 age group showed a higher level of recognition for physical symptom needs and the unemployed group expressed greater needs for information and education. Survivors with multiplicity had greater needs in the domains of healthcare staff and physical symptom. The stress group showed high levels of needs in all domains except religious support. The group with thoughts of suicide showed higher levels of unmet needs for physical symptom.

Conclusion: Most prevalent unmet needs in Korean breast cancer survivors were found in the 'information and education' domain. The 50-59 age group, unemployment, multiplicity, stress and suicidal thoughts were associated with higher levels of unmet needs among Korean breast cancer survivors. Our findings revealed more vulnerable breast cancer survivors with unmet needs and physicians should take a precision approach to satisfy unmet needs of these survivors.
\end{abstract}

Keywords: Unmet need, Breast neoplasm, Survivor

\footnotetext{
* Correspondence: yhj0903@jbnu.ac.kr

†Byung Joo Chae and Jihyoun Lee contributed equally to this study as cofirst authors.

${ }^{8}$ Department of Surgery, Research Institute of Clinical Medicine, Chonbuk National University Hospital, Chonbuk National University and Biomedical Research Institute, 20, Geonji-ro, Deokjin-gu, Jeonju-si, Jeollabuk-do, Korea Full list of author information is available at the end of the article
}

(c) The Author(s). 2019 Open Access This article is distributed under the terms of the Creative Commons Attribution 4.0 International License (http://creativecommons.org/licenses/by/4.0/), which permits unrestricted use, distribution, and reproduction in any medium, provided you give appropriate credit to the original author(s) and the source, provide a link to the Creative Commons license, and indicate if changes were made. The Creative Commons Public Domain Dedication waiver (http://creativecommons.org/publicdomain/zero/1.0/) applies to the data made available in this article, unless otherwise stated. 


\section{Background}

According to the GLOBOCAN report, 18.1 million new cancer cases and 2.1 million (11.6\%) breast cancer cases were projected to occur in 2018 [1]. Among females, breast cancer is the most commonly diagnosed cancer in the vast majority of the countries, accounting for almost 1 in 4 cancer cases. The number of cancer survivors is increasing because the earlier detection and advances in treatment have improved the survival rates of cancer patients. Cancer survivors in Korea are 1.7 million people and breast cancer survivors among them are about 198,000 (11.4\%), representing the fourth largest group among the total cancer survivors [2]. In the situation where over $86 \%$ of Korean breast cancer survivors live more than 10 years after the diagnosis, identifying and satisfying their unmet needs have become an important issue.

The current trends in modern medicine include a shift from a disease-centered model where physicians make all the decisions about the overall aspects of medical services to a patient-centered model where patients actively participate in decisions about diagnosis and treatment and patients' preferences and needs are considered and reflected in medical services. However, there is still a lack of interest in all aspects of the patient as a whole and holistic care is still being neglected [3]. Accurate identification and improvement of unmet needs of cancer survivors not only increase the satisfaction of survivors, but they can also improve the quality of cancer-related medical services. In addition, identifying the factors that affect the unmet needs of cancer survivors is a very important element in the provision of appropriate medical services for them and efficient distribution of medical resources [4].

Major unmet needs of cancer survivors include informational, psychological, physical and social support needs. Informational needs can be attributed to the anxiety and fear of most cancer patients due to a lack of adequate information about their disease and treatment and psychological needs are known to stem from the inability to efficiently cope with the psychological burden generated from the time of cancer diagnosis [5]. Another type of important unmet needs is physical needs and they involve many side effects of cancer treatment, such as nausea, vomiting, sleep disorder, alopecia, and myalgia. These physical difficulties cause many problems of psychological aspects and lead to a decline in quality of life (QoL) among cancer survivors. Active provision of social support for cancer survivors has been shown to not only induce psychosocial adaptation and health promotion behavior but also have a positive effect on the increase of the survival rate [6].

To provide appropriate medical services for cancer survivors, efforts should be made to identify the factors that affect unmet needs as well as specific elements of unmet needs. So far, patients' characteristics, cancer type, stage, treatment modality and time of diagnosis have been presented as the factors affecting the unmet needs of cancer survivors [7-9].

As described above, identifying the unmet needs of cancer survivors and analyzing the related factors are very important for the overall improvement of cancer management. However, to date, most studies on unmet needs have been limited to the analysis of a single factor of unmet needs from a partial point of view and very few studies have dealt with the overall aspects of specific cancer survivors comprehensively.

Therefore, this study aimed to clarify major elements of unmet needs and factors influencing unmet needs from a comprehensive perspective among Korean breast cancer survivors and analyze the relationships between the attributes in order to provide a basis for provision of appropriate medical services for breast cancer survivors.

\section{Methods \\ Study population}

From July 2016 to August 2017, we conducted a crosssectional interview survey with 332 participants who voluntarily agreed to participate in the study and signed the informed consent form among the patients who were diagnosed with breast cancer at six medical centers (Chonbuk National University Hospital, National Cancer Center, Samsung Medical Center, Myongji Hospital, Soonchunhyang University Seoul and Bucheon Hospital) in Korea. Electronic medical records were used to analyze the clinical and pathological factors of subjects and research was conducted after obtaining the approval from the institutional review board of each center. Of the total participants, 320 people $(96.1 \%)$ were included in the final analysis excluding 12 respondents with missing data. Among sociodemographic characteristics of study subjects, income was the average monthly income of household and we investigated into before and after cancer diagnosis. Attendance of self-help group only included actual meeting except online participation. Stress was assessed using the question 'How much stress do you perceive in your daily life?' and answers 'little', 'a little', 'high' and 'very high'. Despair and thought of suicide were evaluated with the following question: 'Have you ever felt serious despair sequentially for more than two weeks in the past year?' and 'Have you ever thought about dying in the past year?'

\section{Measurements}

The needs of breast cancer survivors were assessed by the Comprehensive Needs Assessment Tool (CNAT), which was developed at Korea's National Cancer Center [10]. CNAT is the most appropriate tool to measure the 
needs of Korean cancer survivors which takes into consideration sociocultural aspects. CNAT consists of 59 items, clustered into 8 domains: information and education (10 items), psychological problem (10 items), health care staff (8 items), physical symptom (12 items), hospital service (6 items), family/personal relation problem (3 items), religious/spiritual support (2 items), and social support (8 items) (Additional file 1: Table S1). Subjects responded to each item on a 4-point Likert scale $(0=$ no need, $1=$ low need, $2=$ moderate need, $3=$ high need) based on their experience of the past one month.

QoL was assessed using the EQ-5D validated among Korean subjects, and it was measured using a threepoint scoring system $(1=$ no problems; $2=$ some problems; 3 = severe problems) in five domains: subject's mobility, self-care, usual activities, pain/discomfort and anxiety/depression [11]. Subjects were classified into two groups according to the responses to the questions of the EQ-5D: survivors who had one or more problems and those who had no problems in those areas.

\section{Statistical analyses}

Principle component analysis was used for factor extraction. The eigenvalue was defined as 1 and factor analysis was performed using an orthogonal rotation by the varimax method. T-test and ANOVA were used to compare the need scores for each factor according to the demographic and other characteristics of breast cancer survivors. Multiple regression analysis was conducted to examine the influences of major variables on the level of needs. In multiple regression analysis, the need scores for each factor were used as dependent variables and variables which were shown to be statistically significant by univariate analysis were used as independent variables. All statistical analyses were performed using SPSS version 23.0 (SPSS Inc., Chicago, IL, USA) and the level of statistical significance was set at $p<0.05$.

\section{Results}

\section{Characteristics of the study population}

The age at the time of surgery for breast cancer was $40 \sim 59$ years in 252 people (75.9\%), the time since diagnosis was $1 \sim 3$ years in $48.2 \%$ (160/332 people). $67.8 \%$ (225/332 people) received breast conserving surgery and the majority of the subjects (290 people, $87.4 \%$ ) were early breast cancer survivors of stage II or below. The positive rates of estrogen receptor, progesterone receptor and HER2 were $78.3,72.3$ and $28.6 \%$, respectively. There were 79 cases $(23.8 \%)$ with co-morbidities such as hypertension and diabetes, 141 cases (42.5\%) of patients receiving adjuvant treatment such as chemotherapy, radiation and target therapy after surgery, 144 cases (43.4\%) of patients receiving regular radiological examination after adjuvant treatment, and 47 other cases (14.1\%) (palliative treatment for recurrence, complementary treatment or simple followup) (Table 1).

\section{Factor analysis of needs}

As a result of factor analysis for the needs of the breast cancer survivors, all seven factors were extracted and they were referred to as 'Healthcare staff', 'Information and education', 'Psychological problem', 'Physical symptom', 'Social support', 'Hospital service', 'Religious support' according the contents of the extracted items. As factor analysis showed that one item (Q51) out of 59 items could not be classified as a specific factor, it was excluded from need variables of breast cancer survivors (Additional file 1: Table S2). Among top 10 unmet needs, the 'Information and education' domain included 8 items, and the 'Healthcare staff' domain included 2 items (Table 2). The level of unmet need was highest in the domain 'Information and education' (mean \pm SD; $1.70 \pm 1.14$ ) and the item with the highest level of unmet need was 'Needed help in coping with fear of recurrence' $(2.04 \pm 1.09)$.

\section{Needs by clinicopathological characteristics}

Among age groups, the 50-59 age group showed higher levels of unmet needs in healthcare staff, psychological problem and hospital service and the group with family history of breast cancer had a higher level of hospital service needs. Stage III and IV groups showed higher levels of unmet needs in all domains except healthcare staff, information and education and religious support, the multiplicity group had higher levels of unmet needs in healthcare staff, physical symptom and religious support and HER2 positive breast cancer survivors were found to experience higher levels of unmet needs in social support and hospital service. Patients who underwent target therapy showed higher levels of needs for hospital service and the group of patients receiving palliative treatment for recurrence or complementary treatment showed higher levels of unmet needs in psychological and physical symptoms and social support. However, there were no statistically significant differences in the level of unmet needs according to menopausal status, time since diagnosis, operation method, the presence of estrogen or progesterone receptor, the use of chemotherapy, radiation therapy and hormonal therapy and presence of co-morbidity (Table 3 ).

\section{Needs by sociodemographic characteristics}

Regarding the level of needs according to the marital status, the 'separated' (divorce, separation or bereavement) group was found to have higher levels of unmet needs in the domains of healthcare staff, information and education, psychological problem and the group 
Table 1 Clinicopathological characteristics of study subjects

\begin{tabular}{|c|c|}
\hline Characteristics & Number $(\%$ \\
\hline \multicolumn{2}{|l|}{ Age (years) } \\
\hline$<40$ & $44(13.3)$ \\
\hline $40 \sim 49$ & $129(38.9)$ \\
\hline $50 \sim 59$ & $123(37.0)$ \\
\hline$\geq 60$ & $36(10.8)$ \\
\hline \multicolumn{2}{|l|}{ Menopausal status } \\
\hline Postmenopause & $127(38.3)$ \\
\hline \multicolumn{2}{|c|}{ Time since diagnosis (years) } \\
\hline$\leq 1$ & $73(22.0)$ \\
\hline$>1, \leq 3$ & $160(48.2)$ \\
\hline$>3, \leq 5$ & $66(19.9)$ \\
\hline$>5$ & $33(9.9)$ \\
\hline \multicolumn{2}{|c|}{ Family history of breast cancer } \\
\hline Yes & $27(8.1)$ \\
\hline \multicolumn{2}{|c|}{ Operation method of breast } \\
\hline BCS & $225(67.8)$ \\
\hline Mastectomy & $79(23.8)$ \\
\hline (NA)SSM & $28(8.4)$ \\
\hline \multicolumn{2}{|c|}{ Operation method of axilla } \\
\hline SLNB & $212(63.9)$ \\
\hline ALND & $120(36.1)$ \\
\hline \multicolumn{2}{|l|}{ TNM stage } \\
\hline 0 & $13(3.9)$ \\
\hline । & $129(38.9)$ \\
\hline$\|$ & $148(44.6)$ \\
\hline$I I I \& I V$ & $42(12.6)$ \\
\hline \multicolumn{2}{|l|}{ Multiplicity } \\
\hline Yes & $62(18.7)$ \\
\hline \multicolumn{2}{|l|}{ Estrogen receptor } \\
\hline Positive & $260(78.3)$ \\
\hline \multicolumn{2}{|c|}{ Progesterone receptor } \\
\hline Positive & $240(72.3)$ \\
\hline \multicolumn{2}{|l|}{ HER2 } \\
\hline Positive & $95(28.6)$ \\
\hline \multicolumn{2}{|l|}{ Chemotherapy } \\
\hline Yes & $248(74.7)$ \\
\hline \multicolumn{2}{|l|}{ Hormonal therapy } \\
\hline Yes & $236(71.1)$ \\
\hline \multicolumn{2}{|l|}{ Radiation therapy } \\
\hline Yes & $262(78.9)$ \\
\hline \multicolumn{2}{|l|}{ Target therapy } \\
\hline Yes & $72(21.7)$ \\
\hline \multicolumn{2}{|l|}{ Co-morbidity } \\
\hline Yes & 79 (23.8) \\
\hline
\end{tabular}

Table 1 Clinicopathological characteristics of study subjects (Continued)

\begin{tabular}{lc}
\hline Characteristics & Number (\%) \\
\hline Adjuvant treatment & $141(42.5)$ \\
During & $144(43.4)$ \\
After & $47(14.1)$ \\
Others $^{a}$ &
\end{tabular}

Abbreviations: $B C S$ breast conserving surgery, (NA) (nipple areolar), SSM skin sparing mastectomy, SLNB sentinel lymph node biopsy, ALND axillary lymph node dissection

${ }^{a}$ : Others: palliative treatment for recurrence, complementary treatment or simple follow-up etc

without religion had higher levels of unmet needs in the domains of hospital service, psychological problem, hospital service and religious support. The unemployed group experienced higher levels of unmet needs in all domains except healthcare staff and religious support. In addition, there was no significant difference in the level of unmet needs according to the education level, income before and after diagnosis of breast cancer and joining the self-help group (Table 4).

\section{Needs by psychosocial status and QoL}

Patients with a higher level of stress showed higher levels of unmet needs in all domains except religious support and the group with the experience of despair for more than 2 weeks showed high levels of unmet needs in psychological problem, physical symptom and social support. In addition, the group with thoughts of suicide had higher levels of unmet needs for psychological problems (Fig. 1, Additional file 1: Table S3). The survivors with QoL problems as measured by EQ-5D showed statistically significantly higher levels of unmet needs in all domains except healthcare staff (Fig. 1, Additional file 1: Table S4).

\section{Multiple regression analysis by needs}

Multiple regression analysis was conducted to determine the influence of each independent variable on the total score for each unmet need which was the dependent variable and the results are shown in Table 5 .

The 50s age group showed a higher level of recognition for physical symptom needs and the unemployed group expressed greater needs for information and education. Survivors with multiplicity showed higher levels of needs in the domains of healthcare staff and physical symptom. The stress group showed a higher level of recognition for all needs excluding religious support need. In addition, the group with thoughts of suicide had higher levels of unmet needs for physical symptoms. On the other hand, the differences in the level of unmet needs according to marital status, religion, income, family history, stage, operation method, treatment modality 
Table 2 Top 10 unmet needs of study subjects

\begin{tabular}{llll}
\hline Rank & Item & Score (Mean \pm SD) & Domain \\
\hline 1 & Needed help in coping with fear of recurrence & $2.04 \pm 1.09$ & Information and education \\
2 & Needed information about correct diet (food to eat, food to avoid) & $1.98 \pm 1.11$ & Information and education \\
3 & Needed information about current status of my illness and its future courses & $1.84 \pm 1.14$ & Information and education \\
4 & Needed information or education about things that I can do at home for my health & $1.82 \pm 1.13$ & Information and education \\
5 & Needed information about tests and treatments & $1.80 \pm 1.16$ & Information and education \\
6 & Needed information about symptoms require a hospital visit & $1.79 \pm 1.12$ & Information and education \\
7 & Needed help with worries about treatment sequelae & $1.79 \pm 1.13$ & Information and education \\
8 & Wished to be able to seek doctor in a quick and easy way when in need & $1.78 \pm 1.20$ & Healthcare staff \\
9 & Needed information about financial support for medical expenses from government & $1.77 \pm 1.18$ & Information and education \\
10 & Wished my doctor to be easy, specific, and honest in his/her explanation & $1.74 \pm 1.22$ & Healthcare staff
\end{tabular}

and completion of adjuvant treatment were not statistically significant.

\section{Discussion}

Accurate assessment of the unmet needs of a growing number of cancer survivors worldwide is an important step in developing appropriate interventions to improve QoL. If physicians are aware of the specific unmet needs of each cancer survivor, they can have communication with patients or clients effectively and efficiently, which enables them to perform improved care and effective treatment-related decision making. Therefore, the identification and management of unmet needs is an essential component of high-quality health care for cancer survivors. In the present study, we analyzed the unmet needs and associated factors of Korean breast cancer survivors through a multicenter cross-sectional interview survey.

In the analysis of unmet needs according to the type of cancer, many studies have reported higher levels of unmet needs among breast cancer survivors than other cancer survivors $[12,13]$. This is believed to be due to the fact that the majority of breast cancer survivors are women and people of younger ages, who are generally known to have higher levels of unmet needs than other cancer survivors.

In Korean breast cancer survivors, the level of unmet needs was found to be highest in the domain 'Information and education' and in the item 'Needed help in coping with fear of recurrence.' In Western countries, breast cancer survivors are reported to have high levels of unmet needs for 'psychological problems', but in Eastern countries, the level of unmet needs for 'information and education' is found to be high [14-17], and the results of this study also support such findings of previous studies. This difference between Western and Eastern countries may be thought of as a product of racial and cultural aspects, but in the past, even in Western countries, the level of unmet needs was highest in the domain 'Information and education' [18], so it is thought that the unmet needs for 'information and education' have decreased a result of the improvement in information provision and education for cancer survivors. Therefore, more efforts need to be made to fulfill the needs for information and education in Eastern countries as well. Especially in Korea, the outpatient consultation time for a one-on-one personal consultation and information provision is very short and at most $10 \mathrm{~min}$ in most medical institutions, which is thought to be one of the reasons why the level of unmet needs for 'information and education' is shown to be high. Regarding information needs, increasing the amount of information provided is not always the best solution and since information needs may be a result of cancer survivors' efforts to actively overcome their anxiety or disease, physicians should also pay attention to the problems that information needs stem from and other needs behind them. Most cancer survivors, including breast cancer survivors, have a very high fear of cancer recurrence which is known to be closely associated with unmet needs and QoL $[15,19]$. The results of this study also showed that the level of unmet needs for the item 'Needed help in coping with fear of recurrence' was highest.

Age is a meaningful variable that should be kept in mind when caring for breast cancer survivors. In the study of self-assessed unmet needs, the middle-age group (46-53 years old) expressed statistically significantly higher levels of needs than the older group [20]. This study also revealed that the 50-59 age group had higher levels of unmet needs in the domains of healthcare staff, psychological problem and hospital service compared to other age groups. In addition, the group with the family history of breast cancer had greater needs for hospital service, which may be a result of previous experience of a family member's receiving breast cancer treatment.

In the analysis according to the stage of cancer, the levels of unmet needs in the domains of psychological 


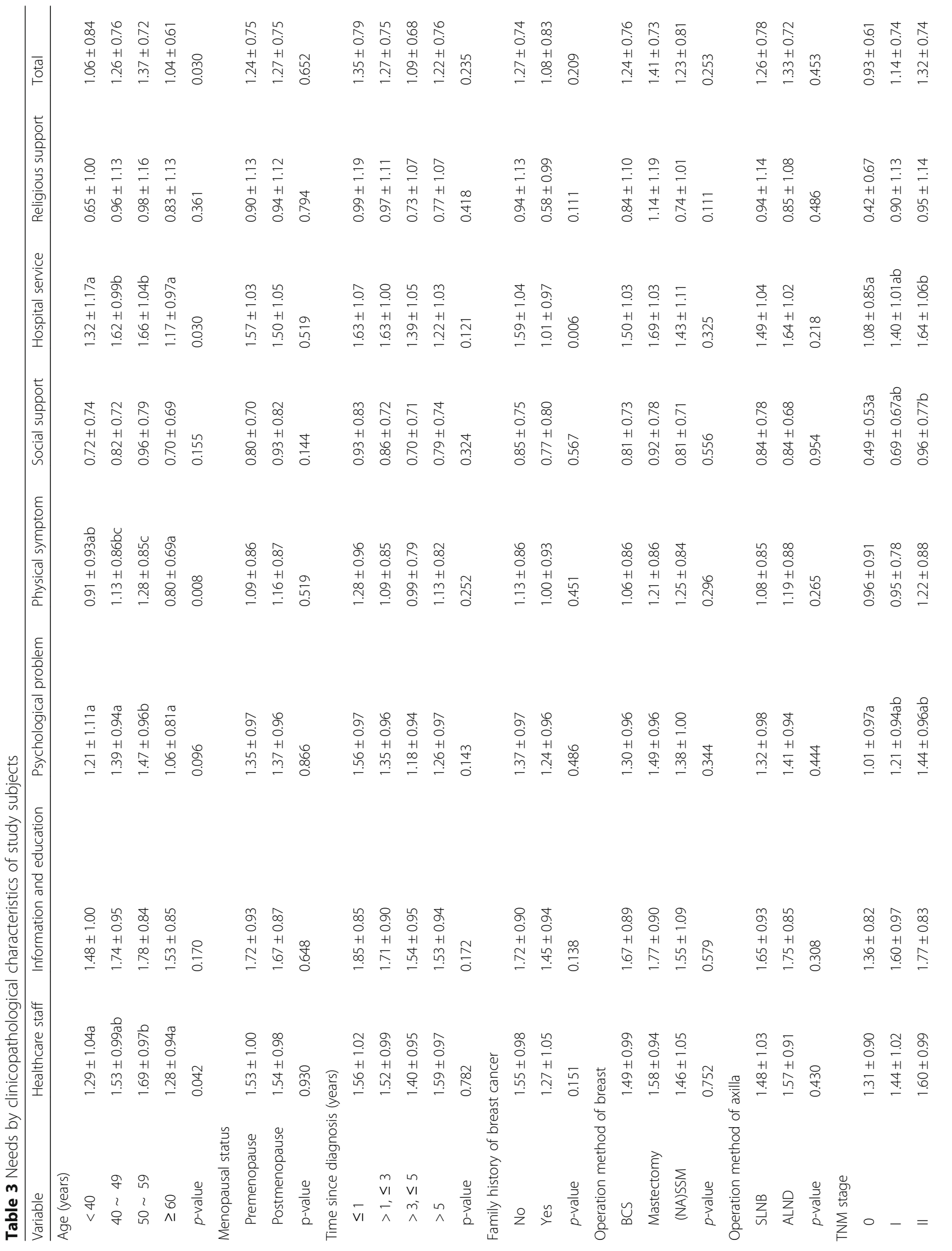




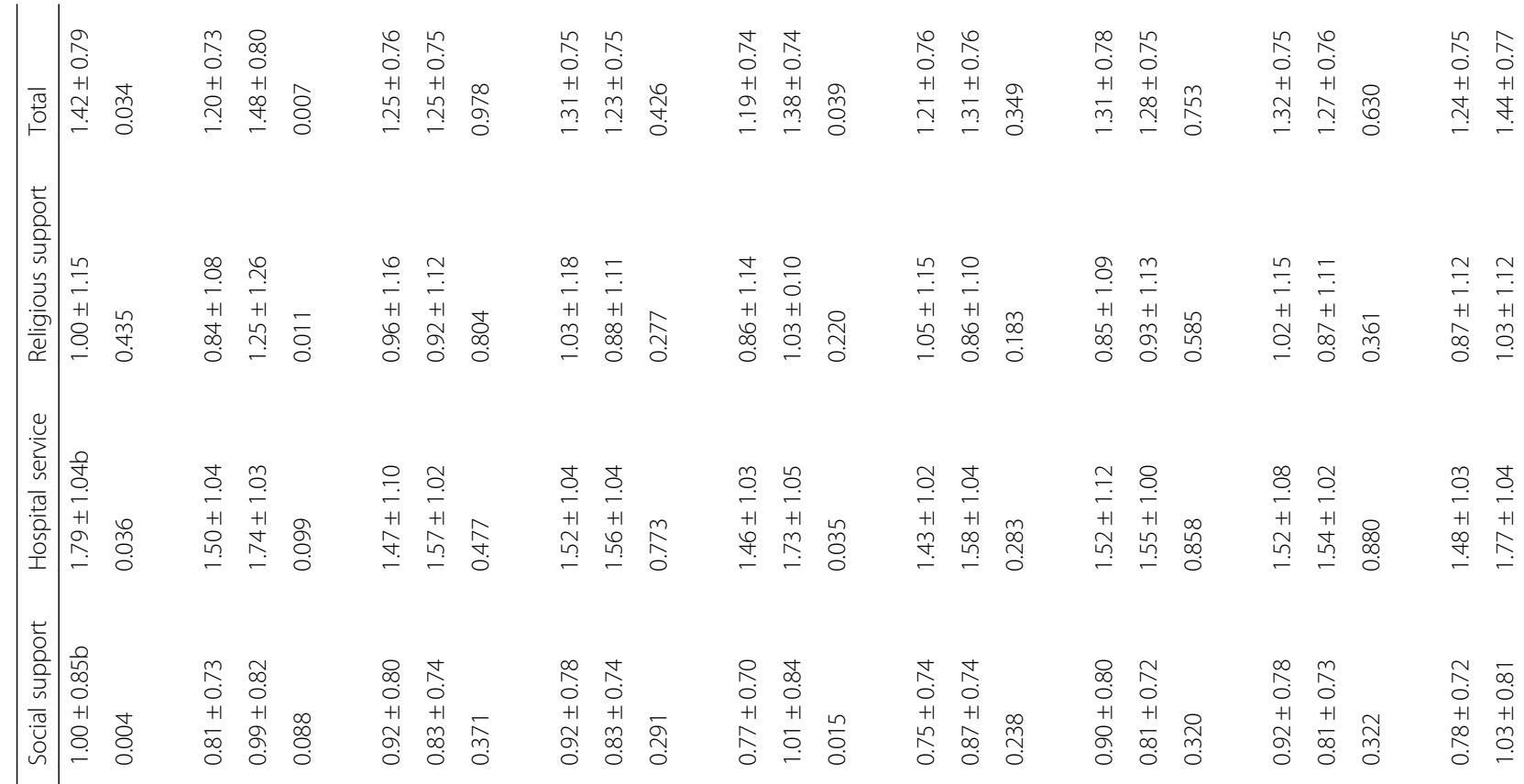

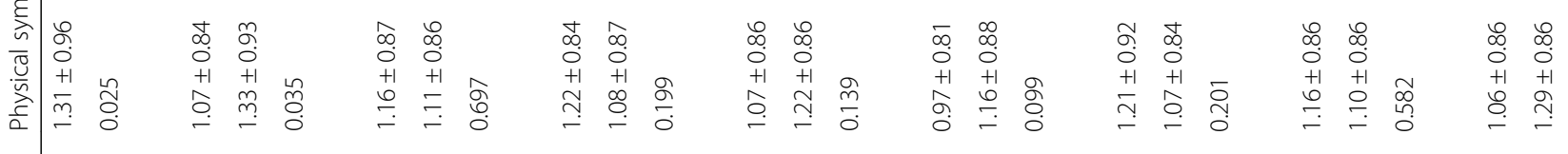

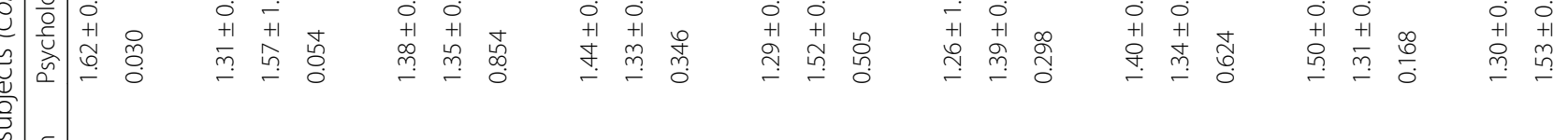

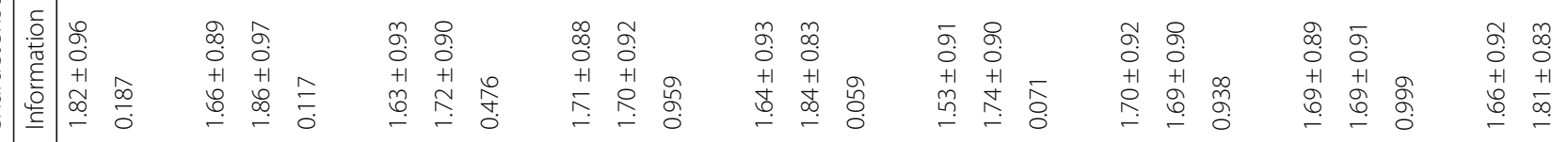




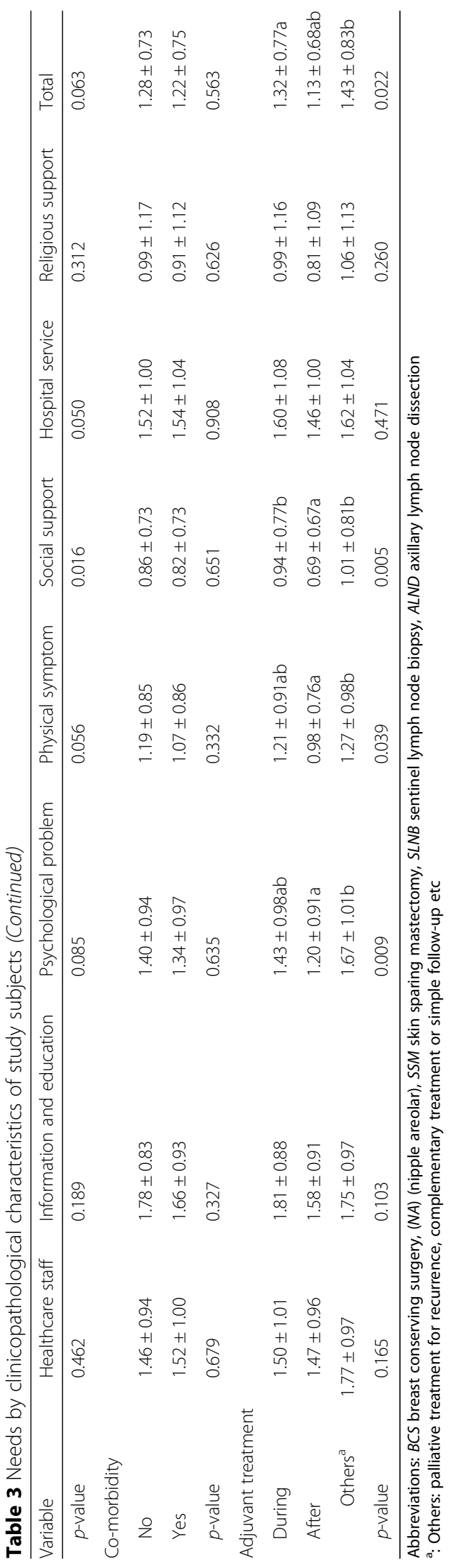




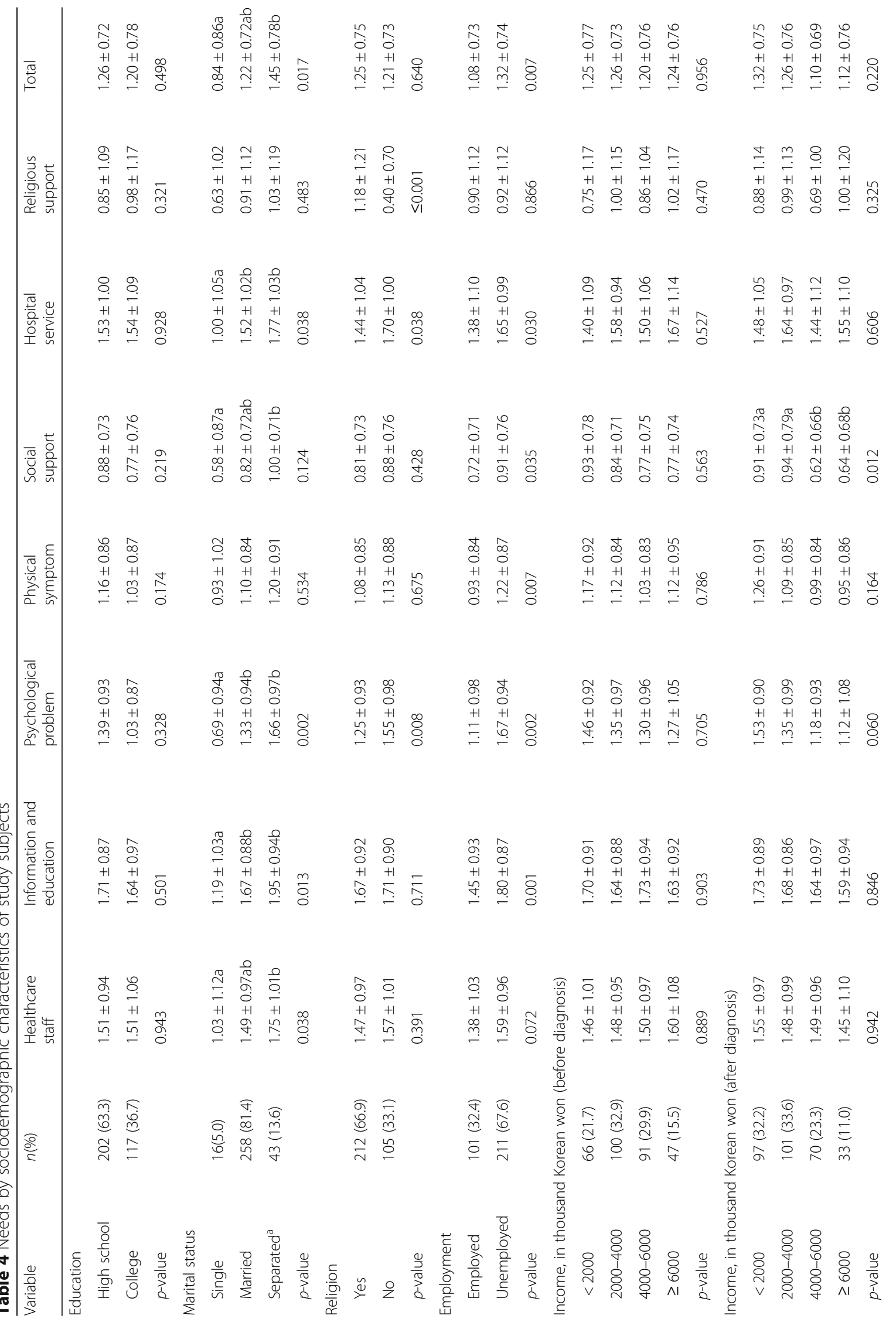




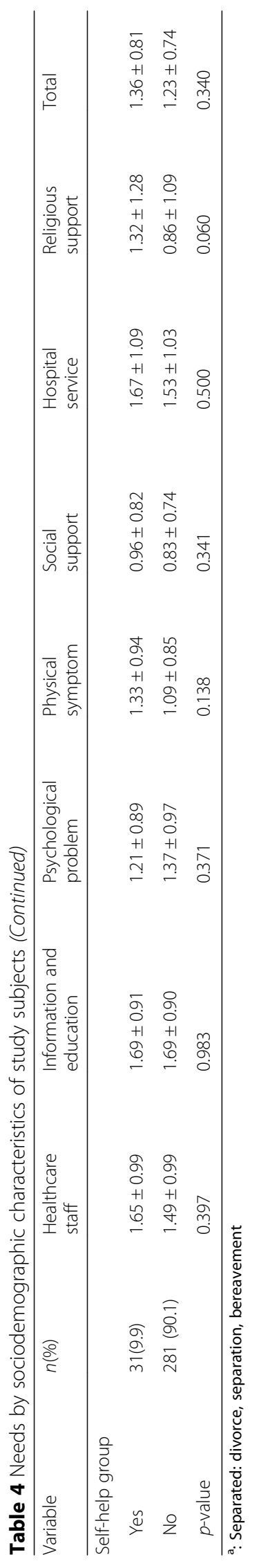


(A)

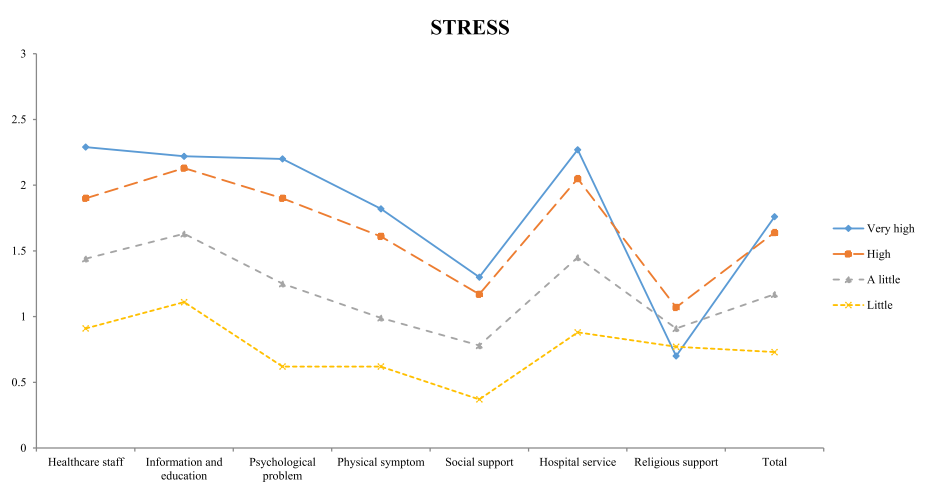

(B)

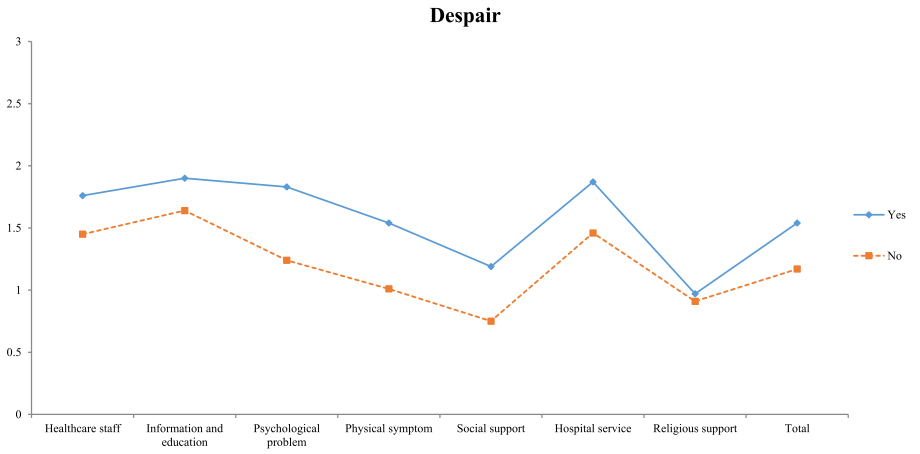

(C)

Thought of suicide

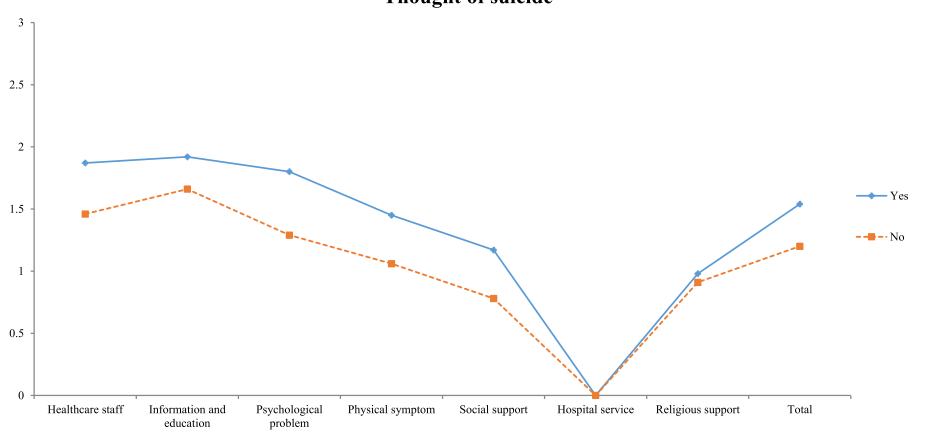

(D)

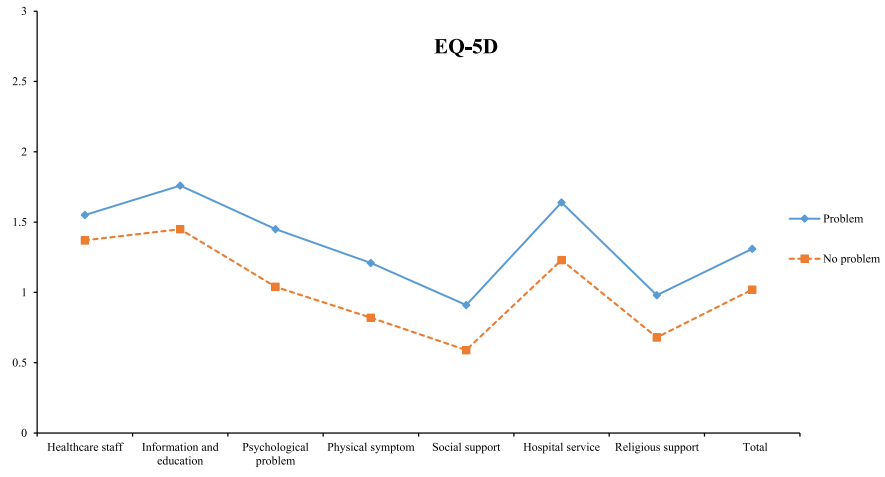

Fig. 1 Needs by psychosocial status and quality of life of study subjects. a Stress (b) Despair (c) Thought of suicide (d) EQ-5D 


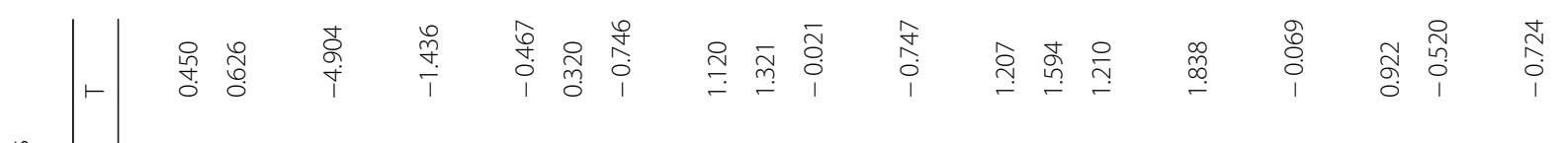

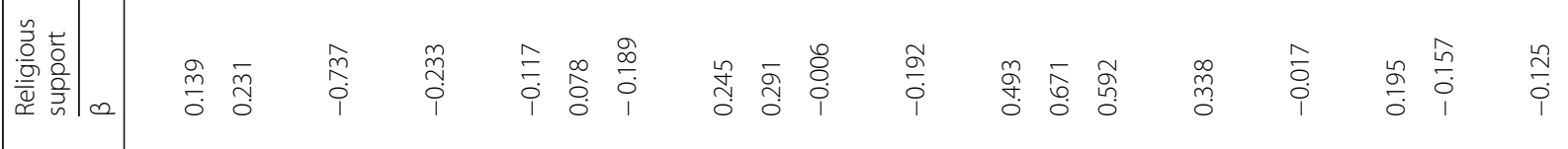

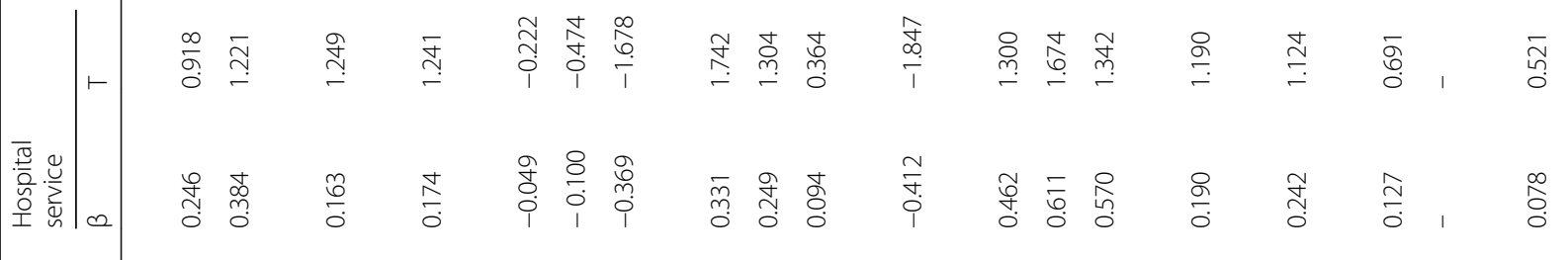

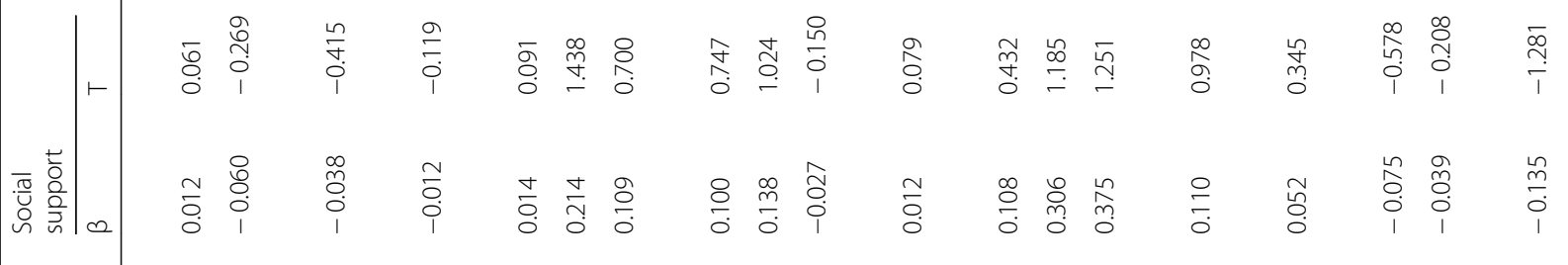

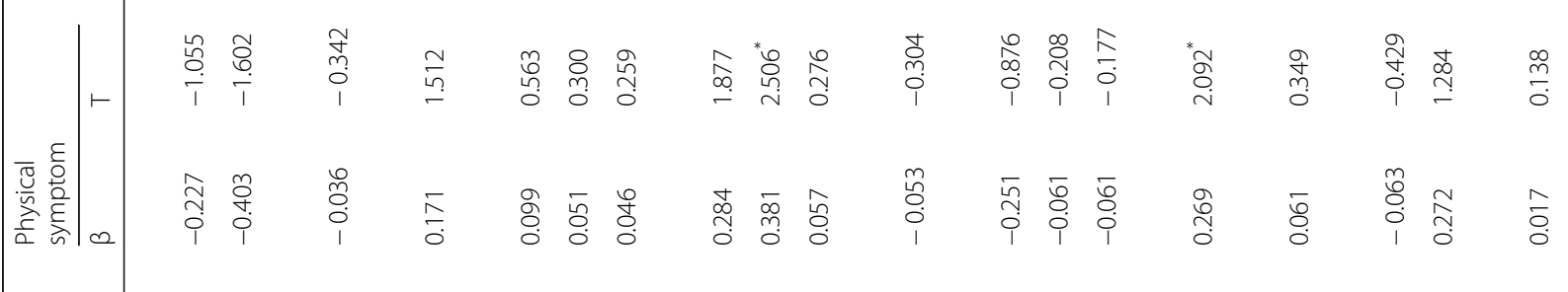

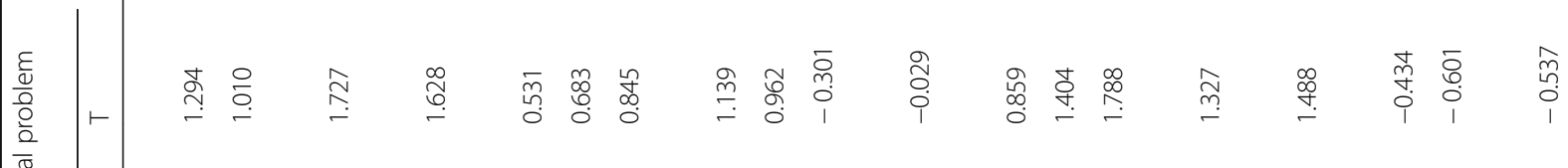

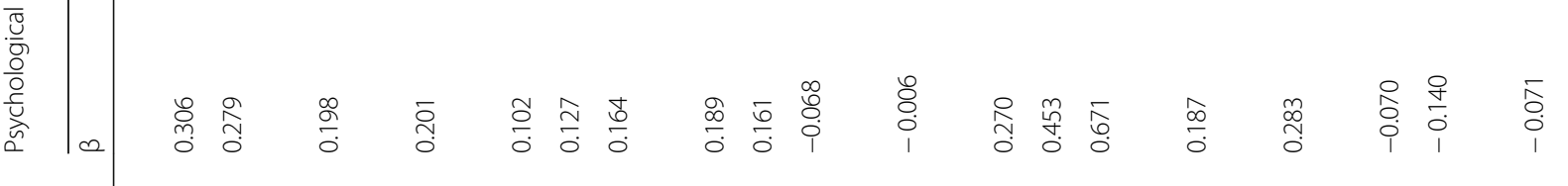

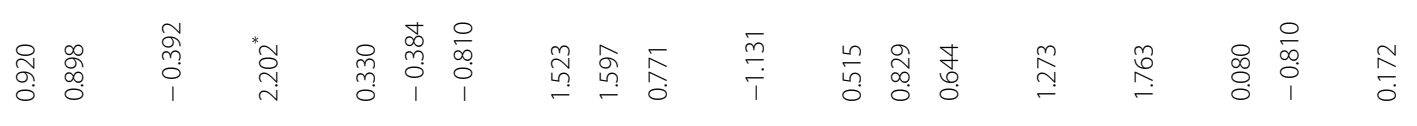

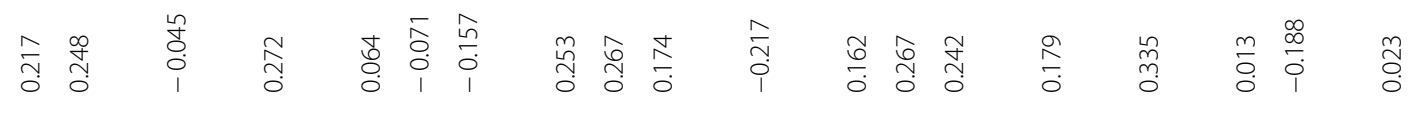

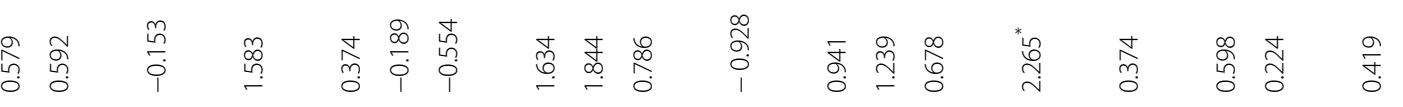

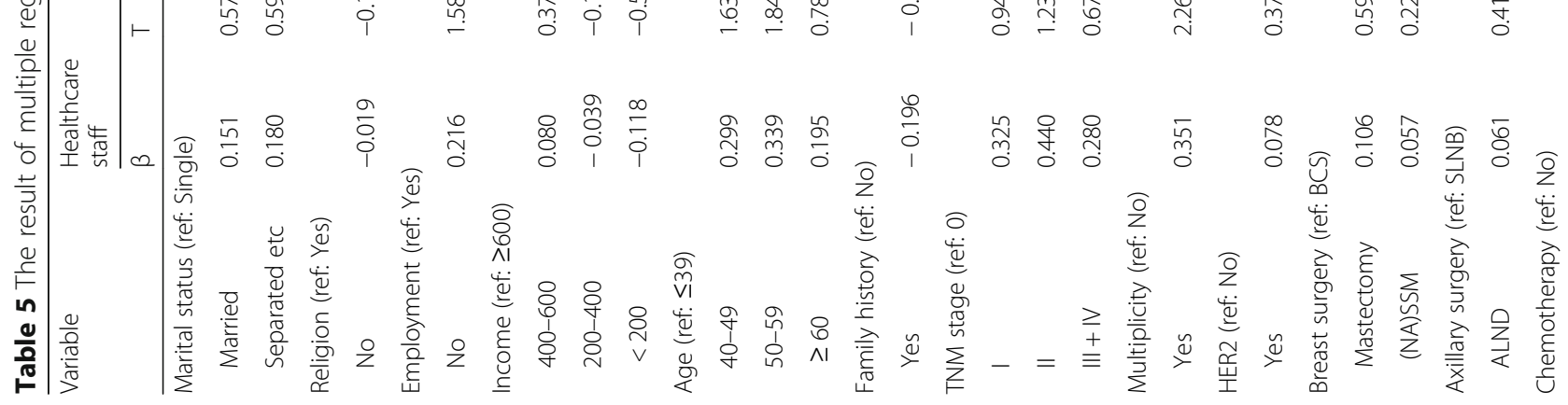




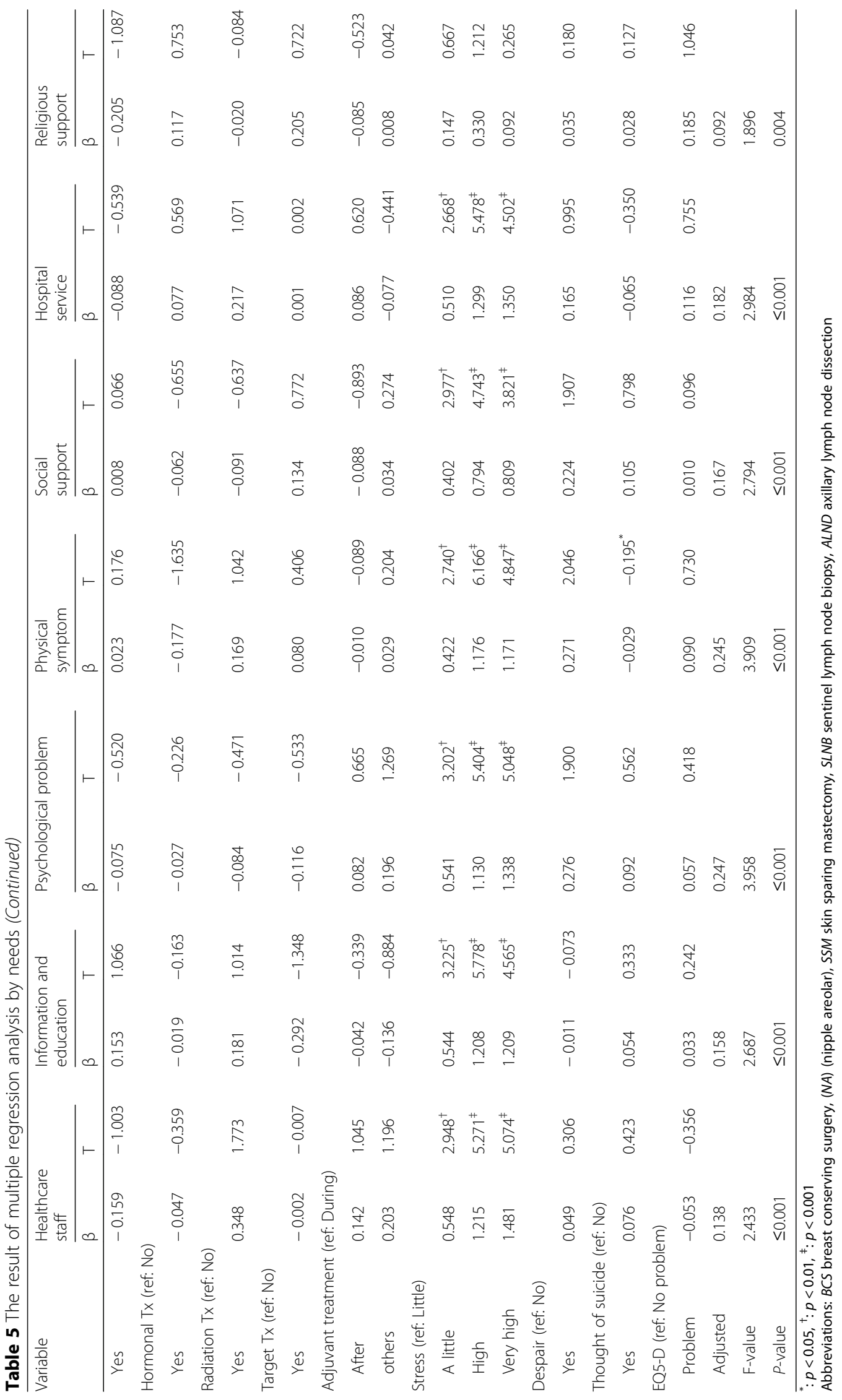


and physical symptoms, social support and hospital service were higher in the group with later stage cancers than the group with earlier stage cancers. This difference can be attributed to the fact that since cancer patients diagnosed at a later stage undergo longer and more complicated treatment causing side effects, have greater fear of recurrence and have more difficulty in performing activities of daily life, they have more needs for the resources of society and medical institutions to help them and other studies have reported the same results $[14,21]$.

Similarly, multiplicity and HER2 positive breast cancer survivors are also thought to have higher levels of unmet needs due to the concerns about high recurrence rates. In particular, survivors receiving target therapy for HER2 positive breast cancers seem to have high hospital service needs because they need to visit a hospital as frequently as once every three weeks for a long period of one year. The group receiving palliative treatment for recurrence or complementary treatment was found to have higher levels of unmet needs in the domains of psychological and physical symptoms and social support and this result is consistent with the findings of the study by Harrison JD et al. [13].

The analysis of needs according to the survival time after breast cancer diagnosis showed no statistically significant differences, but the level of unmet needs was high in the group with the survival time of less than one year. These results seem to show that although many needs may occur due to shock, fear, and anxiety during the initial days after cancer diagnosis, and adjuvant treatment may give rise to various needs, the needs are decreased over time as the patient experiences the process of accepting the changes due to cancer and adapting to life [22]. Therefore, aggressive efforts and measures are needed to meet the unmet needs of survivors during the initial stage after cancer diagnosis.

The spouse can exchange information with the cancer survivor and give comfort to her or him by talking together and exchanging opinions, and help the survivor remember the information provided during the consultation with the physician or treatment. In the case of survivors without the spouse, more unmet needs arise because they have to rely only on medical staff. In this study, we found that the group of people without the spouse had higher levels of unmet needs in the domains of healthcare staff, information and education and psychological problem and hospital service and these results were consistent with previous studies [23].

The group without religion showed higher levels of unmet needs in the domains of 'psychological problem' and 'hospital service ', but they had lower levels of unmet needs in 'religious support.' These results are in agreement with those of other studies [24], and they are thought to indicate that survivors with religion rely on their religion and have interest in spiritual issues to cope with their disease.

For cancer survivors, jobs provide emotional stability through good interpersonal relationships and social life as well as economic benefits of income. In fact, many cancer survivors are known to want to return to work when they have fully recovered and feel ready [25]. In this regard, the results of this study also showed that the unemployed group had higher levels of unmet needs in all need domains except for healthcare staff and religious support, and these results are concordant with the findings of other studies [26].

Distress is the most important psychological issue of breast cancer survivors. In agreement with the findings of previous studies, this study also found that patients with a higher stress level experienced higher levels of unmet needs in most need domains [23, 27, 28]. These results may be attributed to the interaction between two factors; in other words, it is thought that higher levels of unmet needs increased levels of distress. Since the distress level during the initial period after breast cancer diagnosis is a predictor of long-term distress and there is a need to identify survivors more susceptible to distress as soon as possible and implement active interventions [29]. Early diagnosis and active interventions for the mental health status of cancer survivors are imperatively required because psychosocial support for stress and despair prevents distress from proceeding to the thought of suicide.

Estimating QoL is the most common method for ascertaining sequelae in cancer survivors, with studies revealing that the most frequently reported concerns are psychological and social $[30,31]$. There is increasing evidence that unmet needs can have a detrimental effect on QoL of cancer survivors [17, 32]. This study also showed that the group with QoL problem had statistically significantly higher unmet needs in all domains except healthcare staff. Therefore, knowledge about cancer survivors' unmet needs is necessary in order to help survivors attain good QoL.

Lastly, multiple regression analysis was carried out using the total score of unmet need as the dependent variable, and the results revealed that the 50-59 age group, unemployment, multiplicity, stress and thoughts of suicide were associated with higher levels of unmet needs. Therefore, if the quality of cancer management is improved by more actively identifying and meeting unmet needs of these breast cancer survivors, it is expected to increase the satisfaction level among breast cancer survivors and lead to better treatment outcomes.

The present study has several limitations. First, multiple regression analysis showed that although the 
independent variables had a significant relationship, the explanatory power of the model was not high, and this is thought to be due to the small sample size. Second, since this study is a hospital-based study of cancer survivors and only the patients from six medical centers were included in this study, a cautious approach is needed in generalizing the findings of this study to all Korean breast cancer survivors. Third, as a cross-sectional study, this study did not evaluate the cause-effect relationships, and therefore, a longitudinal population-based surveillance study is needed to investigate changes in unmet needs according to the time after breast cancer surgery. Finally, the survivors were recruited by universal sampling, which led to sampling bias. Despites these limitations, this study clarified the specific unmet needs of Korean breast cancer survivors and related factors, and thereby provided the basis for deriving improved treatment outcomes and grounds for providing comprehensive cancer care.

\section{Conclusion}

Most prevalent unmet needs in Korean breast cancer survivors were found in the 'information and education' domain. Especially, the 50-59 age group, unemployment, multiplicity, stress and thought of suicide were associated with higher levels of unmet needs. The efforts to accurately identify breast cancer survivors vulnerable for specific unmet needs and satisfy their unmet needs are expected to improve quality of care for breast cancer survivors and ultimately enable precision treatment that improves the treatment outcomes.

\section{Additional file}

Additional file 1: Table S1. Questionnaires of the Comprehensive Needs Assessment Tool. Table S2. Result factor analysis. Table S3. Needs by psychosocial status of study subjects. Table $\mathbf{S 4}$. Needs by quality of life of study subjects. (DOCX $37 \mathrm{~kb}$ )

\section{Abbreviations

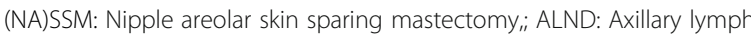 node dissection; BCS: Breast conserving surgery; CNAT: Comprehensive Needs Assessment Tool; QoL: Quality of life; SLNB: Sentinel lymph node biopsy}

\section{Acknowledgments}

We thank the Korean Breast Cancer Survivorship Research Group (Study of Multi-disciplinARy Teamwork of breast cancer survivorship; SMARTSHIP) for their academic contribution to this research, and the patients of the survey for their cooperation.

\section{Authors' contributions}

Conception and design: BJC, JL1 and HJY. Analysis and interpretation of Data: JL2 and HJY. Acquisition of data: JL1, SKL, HS, SJ, JWL, ZK and MHL. Critical revision of the manuscript: BJC, JL1 and HJY. All authors prepared, reviewed and gave critical input into each stage of the manuscript. All authors approved the final version of the manuscript.

\section{Funding}

The present study was supported by grants from the research fund of Korean Society of Surgical Oncology in 2015. The funding body assessed the draft protocol through a peer-review process before awarding the grant. The funding body was not involved in the design of the study, collection, analysis and interpretation of data and preparation of the manuscript.

\section{Availability of data and materials}

The datasets generated and/or analyzed during the current study are not publicly available due owing to data privacy policy at our facility, but are available from the corresponding author on reasonable request.

\section{Ethics approval and consent to participate}

The study was approved by the Institutional Review Board, Chonbuk National University Hospital, Jeonju, Korea (approval number 2016-01-018-004). Written informed consent was obtained from all individual participants included in the study.

Consent for publication

Not applicable

\section{Competing interests}

The authors declare that they have no competing interests.

\section{Author details}

'Department of Surgery, Samsung Medical Center, Sungkyunkwan University school of Medicine, Seoul, Korea. ${ }^{2}$ Department of Surgery, Soonchunhyang University Seoul Hospital, Soonchunhyang University College of Medicine, Seoul, Korea. ${ }^{3}$ Department of Surgery, Myongji Hospital, Goyang, Korea. ${ }^{4}$ Breast Cancer Center, National Cancer Center, Goyang, Korea. ${ }^{5}$ Department of Surgery, Asan Medical Center, University of Ulsan College of Medicine, Seoul, Korea. ${ }^{6}$ Department of Surgery, Soonchunhyang University Bucheon Hospital, Soonchunhyang University College of Medicine, Bucheon, Korea. ${ }^{7}$ Department of Preventive Medicine, Chonbuk National University Medical School, Jeonju, Korea. ${ }^{8}$ Department of Surgery, Research Institute of Clinical Medicine, Chonbuk National University Hospital, Chonbuk National University and Biomedical Research Institute, 20, Geonji-ro, Deokjin-gu, Jeonju-si, Jeollabuk-do, Korea.

Received: 21 March 2019 Accepted: 19 August 2019

Published online: 27 August 2019

\section{References}

1. Bray F, Ferlay J, Soerjomataram I, Siegel RL, Torre LA, Jemal A. Global cancer statistics 2018: GLOBOCAN estimates of incidence and mortality worldwide for 36 cancers in 185 countries. CA Cancer J Clin. 2018:68:394-424.

2. Cancer registry statistics in Korea 2016 available at http://kosis.kr

3. McGlynn EA, Asch SM, Adams J, Keesey J, Hicks J, DeCristofaro A, et al. The quality of health care delivered to adults in the United States. N Engl J Med. 2003;348:2635-45.

4. Wen KY, Gustafson DH. Needs assessment for cancer patients and their families. Health Qual Life Outcomes. 2004;2:11

5. Merckaert I, Libert Y, Messin S, Milani M, Slachmuylder JL, Razavi D. Cancer patients' desire for psychological support: prevalence and implications for screening patients' psychological needs. Psychooncology. 2010;19:141-9.

6. Houts PS, Yasko JM, Kahn SB, Schelzel GW, Marconi KM. Unmet psychological, social, and economic needs of persons with cancer in Pennsylvania. Cancer. 1986;58:2355-61.

7. Mor V, Allen SM, Siegel K, Houts P. Determinants of need and unmet need among cancer patients residing at home. Health Serv Res. 1992;27:337-60.

8. Kurtz ME, Kurtz JC, Given CW, Given B. Loss of physical functioning among patients with cancer: a longitudinal view. Cancer Pract. 1993;1:275-81.

9. Sanson-Fisher R, Girgis A, Boyes A, Bonevski B, Burton L, Cook P. The unmet supportive care needs of patients with cancer. Support Care Rev Group Cancer. 2000;88:226-37.

10. Shim EJ, Lee KS, Park JH. Comprehensive needs assessment tool in cancer (CNAT): the development and validation. Support Care Cancer. 2011;19: 1957-68.

11. Kim MH, Cho YS, Uhm WS, Kim S, Bae SC. Cross-cultural adaptation and validation of the Korean version of the EQ-5D in patients with rheumatic diseases. Qual Life Res. 2005;14:1401-6. 
12. Boyes AW, Girgis A, D'Este C, Zucca AC. Prevalence and correlates of cancer survivors' supportive care needs 6 months after diagnosis: a populationbased cross-sectional study. BMC Cancer. 2012;12:150.

13. Harrison JD, Young JM, Price MA, Butow PN, Solomon MJ. What are the unmet supportive care needs of people with cancer? A systematic review. Support Care Cancer. 2009;17:1117-28.

14. Fiszer C, Dolbeault S, Sultan S, Brédart A. Prevalence, intensity, and predictors of the supportive care needs of women diagnosed with breast cancer: a systematic review. Psychooncology. 2014;23:361-74.

15. Armes J, Crowe M, Colbourne L, Morgan H, Murrells T, Oakley C, et al. Patients' supportive care needs beyond the end of cancer treatment: a prospective, longitudinal survey. J Clin Oncol. 2009;27:6172-9.

16. Cheng KK, Darshini Devi R, Wong WH, Koh C. Perceived symptoms and the supportive care needs of breast cancer survivors six months to five years post-treatment period. Eur J Oncol Nurs. 2014;18:3-9.

17. Hwang SY, Park BW. The perceived care needs of breast cancer patients in Korea. Yonsei Med J. 2006:47:524-33.

18. Whelan TJ, Mohide EA, Willan AR, Arnold A, Tew M, Sellick S, Gafni A, Levine $\mathrm{MN}$. The supportive care needs of newly diagnosed cancer patients attending a regional cancer center. Cancer. 1997;80:1518-24.

19. Ellegaard MB, Grau C, Zachariae R, Bonde JA. Fear of cancer recurrence and unmet needs among breast cancer survivors in the first five years. A crosssectional study. Acta Oncol. 2017;56:314-20.

20. Lindop E, Cannon S. Evaluating the self-assessed support needs of women with breast cancer. J Adv Nurs. 2001;34:760-71.

21. Soothill K, Morris SM, Harman J, Francis B, Thomas C, Mclllmurray MB. The significant unmet needs of cancer patients: probing psychosocial concerns. Support Care Cancer. 2001;9:597-605.

22. Cheng KKF, Wong WH, Koh C. Unmet needs mediate the relationship between symptoms and quality of life in breast cancer survivors. Support Care Cancer. 2016;24:2025-33.

23. Voogt E, van Leeuwen AF, Visser AP, van der Heide A, van der Maas PJ. Information needs of patients with incurable cancer. Support Care Cancer. 2005;13:943-8

24. Mclllmurray MB, Francis B, Harman JC, Morris SM, Soothill K, Thomas C. Psychosocial needs in cancer patients related to religious belief. Palliat Med. 2003; 17:49-54

25. Amir Z, Moran T, Walsh L, Iddenden R, Luker K. Return to paid work after cancer: a British experience. J Cancer Surviv. 2007;1:129-36.

26. Fong EJ, Cheah WL. Unmet supportive care needs among breast cancer survivors of community-based support Group in Kuching, Sarawak. Int J Breast Cancer. 2016;2016:7297813.

27. Schmid-Büchi S, Halfens RJ, Müller M, Dassen T, van den Borne B. Factors associated with supportive care needs of patients under treatment for breast cancer. Eur J Oncol Nurs. 2013;17:22-9.

28. Koopman C, Angell K, Turner-Cobb JM, Kreshka MA, Donnelly P, McCoy R, et al. Distress, coping, and social support among rural women recently diagnosed with primary breast cancer. Breast J. 2001;7:25-33.

29. Lebel S, Rosberger Z, Edgar L, Devins GM. Predicting stress-related problems in long-term breast cancer survivors. J Psychosom Res. 2008;65:513-23.

30. Ganz PA, Desmond KA, Leedham B, Rowland JH, Meyerowitz BE, Belin TR. Quality of life in long-term, disease-free survivors of breast cancer: a followup study. J Natl Cancer Inst. 2002;94:39-49.

31. Baker F, Denniston M, Smith T, West MM. Adult cancer survivors: how are they faring? Cancer. 2005;104:2565-76.

32. Harrison JD, Epplein M, Zheng Y, Zheng W, Chen Z, Gu K, Penson D, et al. Quality of life after breast cancer diagnosis and survival. J Clin Oncol. 2011; 29:406-12.

\section{Publisher's Note}

Springer Nature remains neutral with regard to jurisdictional claims in published maps and institutional affiliations.

Ready to submit your research? Choose BMC and benefit from:

- fast, convenient online submission

- thorough peer review by experienced researchers in your field

- rapid publication on acceptance

- support for research data, including large and complex data types

- gold Open Access which fosters wider collaboration and increased citations

- maximum visibility for your research: over $100 \mathrm{M}$ website views per year

At BMC, research is always in progress.

Learn more biomedcentral.com/submissions 